\title{
E-Learning Experience of Medical and Dental Students from Private Colleges of Karachi, During COVID-19
}

\author{
Sumera Saeed, Beenish Shah, Asma Basharat Ali, Asma Shahid, Ayesha Anis, Batool Sajjad

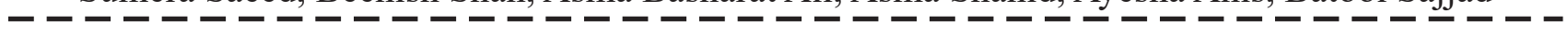
ABSTRACT:

Objectives: To evaluate the IT aptitude of medical and dental students. The secondary objectives were to identify IT related issues faced by students during e-learning sessions,to asssess the perception of e-learning among students and to assess the perception of different e-media among students.

Study design and Setting: A cross-sectional study was conducted among randomly selected MBBS and BDS students of various private Medical and Dental Colleges of Karachi, affiliated with the same University.

Methodology: The sample size was calculated to be 442. Students from the first year to the final year were approached to fill the online pre-tested questionnaire. The data collected was analyzed using SPSS, Version 21. Confidentiality and privacy of the data were maintained. Ethical approval was taken from the relevant boards.

Results: Out of 446 participants, 57.62\% were from MBBS and 42.3\% were from BDS. 96.41\% of students were taking their online classes from their home. Most of the students (56.7\%) preferred mobile phones for these sessions and used broadband or local area network internet connections (55.59\%).

Conclusion: Uninterrupted network connectivity is crucial for the effective implementation of a Virtual Education Program. The Medical and Dental Colleges of a developing country like Pakistan, have a long way to go but with the development of a technologically sound infrastructure, e-learning can prove to be successful in the future

Keywords: COVID-19, e-learning, Distance learning, Online learning, Medical and Dental students, Social distancing, Teaching modalities, Virtual learning environment

- - - - - - - - - - - - - - - - - - - - - - - -

How to cite this Article:

Saeed S, Shah B, Ali AB, Shahid A, Anis A, Sajid B. E-Learning Experience of Medical and Dental Students from Private Colleges of Karachi, During COVID-19. J Bahria Uni Med Dental Coll. 2021; 11(2):76-80 DOI: https://doi.org/10.51985/DAHJ2908

- - - - - - - - - - - - - - - - - - - - - - - - -

This is an Open Access article distributed under the terms of the Creative Commons Attriution Non Commercial Liciense (http:// creativecommons/org/licences/by-nc/4.0) which permits unrestricted non commercial use, distribution and reproduction in any medium, provided the original work is properly cited.

\section{INTRODUCTION:}

The COVID-19 pandemic has sneaked up on the world forcing many nations to enforce a complete lockdown. The public health workforce has urged governments around the

I Sumera Saeed
Lecturer, Department of Health Professions Education (College
of Dentistry),
I Liaquat College of Medicine \& Dentistry
Email: sumerasd@gmail.com
Beenish Shah
Lecturer, Department of Community Medicine
Liaquat College of Medicine \& Dentistry
Asma Basharat Ali
Issistant Professor, Department of Anatomy,
I Jinnah Medical \& Dental College
I Lecturer, Department of Pharmacology
I Liaquat College of Medicine \& Dentistry
I Ayesha Anis
I Lecturer, Department of Health Professions Education
I Biaquat College of Medicine \& Dentistry
Batool Sajjad
I Assistant Professor, Department of Oral Maxillofacial Surgery
I Received: 10-01-2021
I Accepted: 15-03-2021

globe to encourage "Work From Home" and "Social Distancing". This situation has affected the education system worldwide leading to the closure of schools, colleges, and universities alike. ${ }^{2}$ Most of the teaching institutes decided to use distance learning, online programs to continue and complete the planned curriculum. ${ }^{3,4}$ Although in the last decade or so, there had been many suggestions but no successful inculcation of e-learning in the Medical and Dental institutes of Karachi, and with the current lockdown, many of these institutes has been done. With no choice but to resort to e-learning with very little guidance to refer to. ${ }^{5}$ E-learning methods provide a medium for the transmission of information and skills using electronic applications. ${ }^{6}$ Various online learning tools and applications have been explored for their effectiveness in teaching and learning. ${ }^{7,8}$ Studies have proved that along with the presence of tools and applications, technological accessibility and a good internet connection are essential in making online learning a success. ${ }^{7,9}$.

The switch from Traditional Learning Environment to Virtual Learning Environment (VLE) is not an easy one. It requires not only the latest gadgets and devices, proper internet connection, and recording facilities but also techno-savvy faculty and students and infrastructure to facilitate online 
Sumera Saeed, Beenish Shah, Asma Basharat Ali, Asma Shahid, Ayesha Anis, Batool Sajjad

teaching and learning. ${ }^{4}$

Medical and Dental Colleges' administrators and teachers are taking appropriate measures to conduct effective elearning via e-lectures, e-tutorials, case-based e-learning, etc. so that continuous education can be provided without getting much affected during the quarantine period. ${ }^{7,8,10}$ Therefore, the objectives of our study were to evaluate the IT aptitude of medical and dental students. The secondary objectives were to identify IT related issues faced by students during e-learning sessions, to asssess the perception of elearning among students and to assess the perception of different e-media among students.

\section{METHODOLOGY:}

A cross-sectional study was conducted among randomly selected MBBS and BDS students of various private Medical and Dental Colleges of Karachi, affiliated with the same University.

The face and content validity of the questionnaire was established through expert opinions of Medical Educationists and pilot testing which was done to pre-test the questionnaire among the sample of 40 students and they were not included in the main study. Necessary changes were made in the questionnaire. Cronbach's alpha (0.8) was used to measure internal consistency.

The sample size was calculated to be 442 (using Calculator.net) with a $95 \%$ confidence interval and a $5 \%$ error margin. All the registered students from the first year to the final year were approached to fill the online pre-tested questionnaire. Students who consented to participate, their responses were collected. Confidentiality and privacy of the data were maintained. Ethical approval was taken from the relevant boards. Medical \& Dental students taking online sessions during COVID-19 lockdown were included in the study. Students who did not agree to participate were excluded. The data collected was entered and analyzed using the statistical package SPSS, Version 21. Since the data was collected through convenient sampling and normality was not known, the non-parametric tests (Mann-Whitney U and Kruskal Wallis test) were applied for the analysis.

\section{RESULTS:}

The survey was conducted among 446 students of all years of MBBS \& BDS, in different Medical and Dental colleges affiliated with the same University thus following the same curriculum. In this survey $57.62 \%$ MBBS and $42.38 \%$, BDS students participated. The age of the students ranged from 17-28 years with a mean age of $20.29+1.6$. Out of these participants, $64.35 \%$ were females and $35.65 \%$ were males.

During COVID-19 enforced online learning sessions $96.41 \%$ of students were taking their classes from their home whereas $3.59 \%$ of students were attending their classes either from the hostel or from some relative's house.

In most of the institutes (74.7\%) Zoom video conferencing application is being used for student's online sessions whereas $22.2 \%$ of the students attended recorded lectures either through college portals or direct through YouTube recordings .for e-learning session. Many students preferred smartphones $(56.7 \%)$ for their online learning sessions whereas $21.5 \%$ students use laptops and $12.5 \%$ use both laptops and smartphones for their sessions. Around $46 \%$ of students faced internet disruption multiple times a day which affects their learning process. However, $42 \%$ of students faced internet disruption one to two times a day or in a week. A few students around $12 \%$ said that they never had internet disruption. The internet disruption was found to be more evident with a signal-based internet connection (44.6\%) while the most consistent one was Optical fiber which was least disrupted (4\%) but was used by the least amount of students. Where significant value á $=0.05$ and grouping variable: Discipline scale

From this data, it can be concluded that teaching using images was more beneficial for learning in the MBBS than it was in BDS. It was proven through the Mann-Whitney U test where the result was statistically significantly higher in MBBS $(\mathrm{U}=20817, \mathrm{p}=.007)$. A Kruskal-Wallis $\mathrm{H}$ test showed that there was a statistically significant difference in improvement in learning through e-learning among the different academic years of BDS, (Chi-square $=12.697, \mathrm{p}$ $=0.005$ ), with a mean rank in improvement in learning through e-learning of 91.78 for the First Year, 114.00 for Second Year, 100.20 for Third Year and 70.21 for fourth Year BDS. A Kruskal-Wallis H test showed that there was a statistically significant difference in improvement in learning through e-learning among the different academic years of MBBS, (Chi-square $=14.565, p=0.006)$, with a mean rank in improvement in learning through e-learning of 213.96 for First Year, 230.10 for Second Year, 262.04 for Third Year and 190.98 for fourth Year and 170.65 for final year.

As for the benefit of these sessions, the majority (53.3\%) of students agreed that these online classes have proved beneficial during the COVID-19 lockdown.

\section{DISCUSSION:}

Pakistan with its first reported case of COVID 19 on 24th February 2020, was quick to close down its educational institutes on 27th February, 2020. ${ }^{11}$ The lockdown was further imposed in phases by March. ${ }^{11}$ It allowed students to move back to their homes promptly, owing to the $96.41 \%$ of students attending online lectures from home. A similar condition happened in neighboring countries where educational institutions were closed first and later on lockdown was imposed in the country..$^{10}$ The situation is quite the opposite for other countries where sudden lockdowns were imposed. ${ }^{4,12}$

By mid-March, most of the Universities including medical institutions and their affiliated colleges adopted Virtual 
Figure 1: Shows the internet connection preferred by students during E-learning session

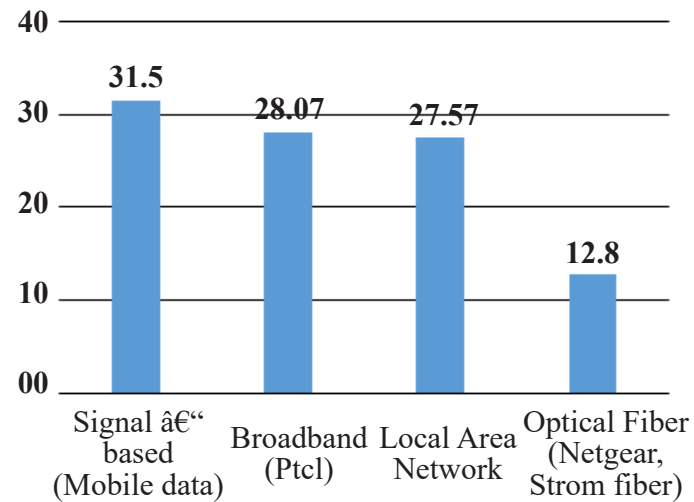

Table 1: Comparison between different e-learning media used for MBBS and BDS students

\begin{tabular}{|c|c|c|c|c|}
\hline $\begin{array}{c}\text { Use of images } \\
\text { in lectures }\end{array}$ & $\begin{array}{c}\text { Demonstration } \\
\text { videos }\end{array}$ & $\begin{array}{c}\text { Recorded } \\
\text { lectures }\end{array}$ & $\begin{array}{c}\text { Live } \\
\text { lectures }\end{array}$ & $\begin{array}{c}\text { Live } \\
\text { discussion } \\
\text { / tutorial }\end{array}$ \\
\hline 20817.5 & 23529.50 & 22263.5 & 22013.5 & 21627 \\
\hline 0.007 & 0.557 & 0.121 & 0.407 & 0.256 \\
\hline
\end{tabular}

Table 2: e-learning among the different academic years of BDS

Kruskal Wallis Test

\begin{tabular}{|l|l|}
\hline & e-learning improved my learning \\
\hline Chi-square & 12.69 \\
\hline df & 3 \\
\hline Asymp. Sig. & 0.005 \\
\hline
\end{tabular}

Grouping Variable: New Acad Year

Table 3: e-learning among the different academic years of MBBS Kruskal Wallis Test

\begin{tabular}{|l|l|}
\hline & e-learning improved my learning \\
\hline Chi-square & 14.56 \\
\hline df & 4 \\
\hline Asymp. Sig. & 0.006 \\
\hline
\end{tabular}

Grouping Variable: New Acad Year

Learning Environment (VLE). VLE learning can be either commercial or open-source. ${ }^{13} \mathrm{VLE}$ includes Asynchronous, Synchronous, and blend of both. A lot of institutions went out for Synchronous e-learning via open sources due to their financial constraints. ${ }^{3,14}$ Multiple applications were used for this purpose such as Google Classroom, TEAMS, Google Hangouts, and Zoom video conferencing service. ${ }^{15,16} \mathrm{Zoom}$ was the most commonly used one in medical institutions as was evident in our study where $74.6 \%$ were attending a blend of synchronous and asynchronous learning through live Zoom Session as well as their recordings. The remaining $22.2 \%$ of the students are attending asynchronous eLearning via recorded lectures either through college portals or directly by YouTube recordings.
Mobile phones were the device of choice among our students $(56.7 \%)$ which was comparable to the study conducted in Turkey (2016) where $95.5 \%$ of students preferred smartphones. ${ }^{17}$ This preference of smartphones over desktops/laptops was due to its flexibility of use anywhere and anytime as well as it being a cheaper gadget as compared to Desktop/laptop which was proven in a study done in Pakistan. ${ }^{18}$

The success of e-learning adoption is also highly dependent on technological accessibility and good internet connection(Saudi and others). Previous studies have reported that connectivity issues limited the use of e-learning. ${ }^{19,20}$ There are various forms of internet connections available in Karachi: broadband, Local Area Network, 3G or 4G mobile connection, and Optical fiber network. The data showed $55.59 \%$ of our students used broadband and Local Area Network and $31.8 \%$ used $3 \mathrm{G}$ or $4 \mathrm{G}$ mobile connection. Signal-based internet connection $(3 \mathrm{G} / 4 \mathrm{G})$ was linked more with connectivity problems (44.6\%) as compared to Optical fiber network (4\%), which was used by only $12 \%$ of our students. Most of the students (46\%) faced multiple disruptions per day while few students $(24.9 \%)$ faced fewer disruptions in connectivity per day.

The skills enhancement and development program for educators and learners to use technology in education is an important factor for the success of e-learning as discussed in other studies. ${ }^{7,924,25}$

Students in this study reported a greater perceived level for computer skills and learning management systems similar to a study conducted in Saudi Arabia. ${ }^{26 .}$

This study shows that using more images for e-lectures helps students for better understanding of lectures as some articles also considered the images to be one of the important media which can enhance the retention of information and its retrieval. Hence it should be used accordingly to create interest. These images can be accompanied by scarce bulleted text. $^{27}$

E-learning has a well-established role in medical education and it is effective in enhancing learning and is well accepted by students. ${ }^{28}$ Table 2 and 3 of the results of the survey also show the significant improvement in learning through elearning among the different academic years of medical and dental students.

According to our survey, $53.3 \%$ of students agreed that online sessions proved beneficial during COVID-19 lockdown. The studies that were done in 2016 and 2019 in Pakistan also showed a willingness to adopt online learning among students. ${ }^{21,22}$ The inculcation of e-learning is dependent upon a proper technical infrastructure with the availability of high-speed, uninterrupted internet connection to the students as well as appropriate use of different e-learning media to deliver information. ${ }^{23}$ 
The limitations of this study were that the government institutes were not included and since it was online survey participation by all students could not be ensured. The technological capabilities of the students were not taken into consideration and the reason for the preference for using mobile phones was not explored.Further studies on comparison among different undergraduate years regarding willingness to adopt online learning are required.

\section{CONCLUSION:}

Students found the online sessions useful during the COVID19 lockdown. Uninterrupted network connectivity is crucial for the effective implementation of a Virtual Education Program. The Medical and Dental Colleges of a developing country like Pakistan has a long way to go but with the development of a technologically sound infrastructure, e-learning can prove to be successful in the future. Using different e-learning media improves understanding of a topic. The training of students in regards to Information and Communication Technology (ICT)plays an important role in the success of online teaching.

I Authors Contribution: | Sumera Saeed: Conception or design of study, revision and | final approval

Beenish Shah: Conception or design of study, analysis, revision I and final approval

I Asma Basharat Ali: Conception or design of study, revision and final approval

Asma Shahid: Conception or design of study, interpretation, I revision and final approval

I Ayesha Anis: Drafting the work, data collection

Batool Sajjad: Drafting the work, data collection, revising the work critically for important intellectual content

I - - - - - - - - - - - - - - I

\section{REFERENCES:}

1. Bedford J, Enria D, Giesecke J, Heymann DL, Ihekweazu C, Kobinger G, et al. COVID-19: towards controlling of a pandemic. The Lancet. 2020;395(10229):1015-8.

2. News. UNESCO. COVID-19 Educational Disruption and Response. Available from: https://en.unesco.org/news/covid19-educational-disruption-and-response [Accessed on 6 April 2020].

3. Abbasi MS, Ahmed N, Sajjad B, Alshahrani A, Saeed S, Sarfaraz S, Alhamdan RS, Vohra F, Abdul Jabbar T. E-Learning perception and satisfaction among health sciences students amid the COVID-19 pandemic. Work. 2020;67(3):549-556

4. Sahu P. Impact on Education and Mental Health of Students and Academic Staff. Closure of Universities Due to Coronavirus Disease 2019 (COVID-19). Cureus. 2020;12(4):e7541.

5. HEC Covid-19 Policy Guidance No.5 (Online Readiness). Available from: https://www.hec.gov.pk/english /HECAnnouncements/Documents/nCoVirus/Covid-19-PolicyGuidance-No.5-Online\%20Readiness.pdf [Accessed on 6 April 2020].

6. Ghanizadeh A, Mosallaei S, Dorche MS, Sahraian A, Yazdanshenas P. Attitude and Use of E-Learning, education by medical students in Shiraz, Iran. Intern Med Med Invest J. 2018;3(3):108-11.
7. Linjawi AI, Alfadda LS. Students' perception, attitudes, and readiness toward online learning in dental education in Saudi Arabia: a cohort study. Adv Med Educ Pract. 2018;9:855.

8. George PP, Papachristou N, Belisario JM, Wang W, Wark PA, Cotic Z, et al. Online eLearning for undergraduates in health professions: a systematic review of the impact on knowledge, skills, attitudes and satisfaction. J Glob Health. 2014;4(1):010406.

9. Linjawi AI, Walmsley AD, Hill KB. Online discussion boards in dental education: potential and challenges. Eur J Dent Educ. 2012;16(1):e3-9

10. Kapasia N, Paul P, Roy A, Saha J, Zaveri A, Mallick R, Barman B, Das P, Chouhan P. Impact of lockdown on learning status of undergraduate and postgraduate students during COVID-19 pandemic in West Bengal, India. Child. Youth Serv. Rev. 2020;116:105194.

11. Worldometer. COVID-19 CORONAVIRUS PANDEMIC. Available from: https://www.worldometers. info/coronavirus /country/pakistan/ [Accessed on 5 th May 2020]

12. Quazi AH. Coronavirus update: Anxiety and a lot of time to study for students stuck in coaching hub Kota. Available from: https://www.hindustantimes.com/india-news/anxiety-and-alot-of-time-to-study-for-students-stuck-in-coaching-hubkota/story-qVwAzrHh1SgIA36JXwfwXO.html [Accessed on 5th May 2020]

13. Jawaid M, Aly SM. 'E-learning' modalities in the current era of Medical Education in Pakistan. Pak J Med Sci. 2014;30(5):1156.

14. Lakhan SE, Jhunjhunwala K. Open Source Software in Education. EDUCAUSE Quarterly. 2008;31(2):33-40

15. Taha MH, Abdalla ME, Wadi M, Khalafalla H. Curriculum delivery in Medical Education during an emergency: A guide based on the responses to the COVID-19 pandemic. MedEdPublish. 2020;16:9.

16. Barbera $\mathrm{E}$, Clarà $\mathrm{M}$. Time in e-Learning Research: A Qualitative Review of the Empirical Consideration of Time in Research into e-learning. International Scholarly Research Notices. 2012;2012.

17. Yilmaz O. E-Learning: Students Input for Using Mobile Devices in Science Instructional Settings. J Educ Learn. 2016;5(3):182-92.

18. Iqbal S. Mobile phone usage and students' perception towards m-learning: A case of undergraduate students in Pakistan. Am J Distance Educ. 2017:25;32(1).

19. Almarabeh T, Rajab L, Majdalawi YK. Awareness and usage of computer and internet among medical faculties' students at the University of Jordan. J Eng App. 2016;9(05):147.

20. Akram W, Adeel S, Tabassum M, Jiang Y, Chandio A, Yasmin I. Scenario Analysis and Proposed Plan for Pakistani Universities-COVID-19: Application of Design Thinking Model. Cambridge Open Engage. 2020. Advanced online publication. Doi: 10.13140/RG.2.2.27794.61127.

21. Iqbal S, Shafiq A, Iqbal N. Perceptions of undergraduate dental students towards e-Learning in Lahore Medical and Dental College. Pak J Med Sci. 2016;10(4):1191-3.

22. Sethi A, Wajid A, Khan A. E-LEARNING: ARE WE THERE YET?. Prof Med J. 2019;26(04):632-8. 
E-Learning Experience of Medical and Dental Students from Private Colleges of Karachi, During COVID-19

23. Tedre M, Ngumbuke F, Kemppainen J. Infrastructure, human capacity, and high hopes: A decade of development of eLearning in a Tanzanian HEI. RUSC. UnivKnowSoc J. 2010;7(1):7-20.

24. Al-Harbi KRAS. Investigating Factors Influencing the Adoption of E-learning: Saudi Students' Perspective. Leicester: University of Leicester; 2011.

25. Eaton KA, Reynolds PA, Grayden SK, Wilson NH. A vision of dental education in the third millennium. British dental journal. 2008;205(5):261-71
26. Alsuraihi AK, Almaqati AS, Abughanim SA, JastaniahNA.Use of social media in education among medical students in Saudi Arabia.Korean J Med Educ. 2016 Dec; 28(4):343-354.

27. Norris EM. The constructive use of images in medical teaching: a literature review. JRSM Short Reports. 2012;3(5):1-8

28. Choules AP. The use of elearning in medical education: a review of the current situation. Postgrad Med J. 2007;83(978):212-6.

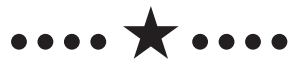

